\title{
Patterns of GPS-TEC variation over low-latitude regions (African sector) during the deep solar minimum (2008 to 2009) and solar maximum (2012 to 2013) phases
}

\author{
Yekoye Asmare Tariku
}

\begin{abstract}
Due to the unique geometry of the geomagnetic fields near the magnetic equator and low-latitude regions, the satellite communication system in the African sector is strongly influenced by the effects resulting from the accumulation of electrons in their ionosphere. Hence, this paper investigates the patterns of the vertical total electron content (VTEC) variation detected by the Global Positioning System (GPS) over low-latitude regions during a very low (2008 to 2009) and a high solar activity (2012 to 2013) phases. The study has been carried out by considering eight ground-based dual-frequency GPS receivers installed recently at different regions in Ethiopia. In this work, the diurnal, monthly, and seasonal variations in the GPS-VTEC have been analyzed. It has been found that the diurnal variability of VTEC has shown minimum values at around 0300 UT (0600 local time (LT)) and maximum values nearly between 1000 and 1300 UT (1300 and 1600 LT) during both the low and the high activity phases. Moreover, the maximum and minimum of monthly mean hourly VTEC values are observed in October and July, respectively, during both the low (2009) and the high solar activity (2012) phases. It has also been depicted that seasonal mean hourly VTEC values have shown maxima and minima in the March equinox and the June solstice, respectively, during both the low and the high solar activity phases.
\end{abstract}

Keywords: Vertical TEC; GPS; Low solar activity; High solar activity; lonosphere

\section{Background}

Ionosphere is the ionized region of the Earth's upper atmosphere where there are sufficient number of free electrons that can largely affect the propagation of radio waves. Hence, acting as a dispersive medium, the ionosphere has great influence on the satellite navigation and communication. This influence is directly proportional to the density of free electrons which could change the phase and strength of electromagnetic radio frequency waves. According to Bagiya et al. (2009), when the satellite signal propagates through the ionosphere, the carrier experiences a phase advance and the code experiences a group delay due to the accumulation of electrons along the path of the signals from the satellite to the receiver. As a result, the carrier phase pseudo ranges are measured too short, and the code pseudo ranges are measured too long compared to the geometric range

Correspondence: yekoye2002@gmail.com

Department of Physics, Ambo University, P.O. Box 19, Ambo, Ethiopia between the satellite and the receiver, which induces a significant range error in the positioning and navigation system.

Due to the unique geometry of the geomagnetic fields, these effects are more pronounced near the magnetic equator and low-latitude regions such as the African regions. In such regions, the satellite communication system is largely affected by the effects resulting from the accumulated electrons in their ionosphere. Moreover, the daytime ionosphere is characterized by an $\mathrm{F}$ region electron density trough at the geomagnetic equator and two crests within $\pm 20^{\circ}$ magnetic latitudes which is formed due the so-called fountain effect (Moffett and Hanson 1965). The African sector, in general, has the largest landmass under the equatorial anomaly strip, with an ionosphere that is characterized with complex electrodynamic structures that are not yet well understood. Perhaps, this could be largely due to the sparse results of ionospheric studies from the continent.

Among all parameters that exist in the ionosphere, the TEC largely affects the electromagnetic waves propagating 
through the ionosphere. Hence, TEC studies have got a new impetus with the advent of GPS-based navigation and ground positioning that uses trans-ionospheric communication. Since ionospheric TEC largely relies on the state of the ionosphere, it has an overbearing influence on the GPSbased communications. TEC is the total number of electrons integrated along the path from the receiver $(\mathrm{R})$ to the GPS satellites (S) and usually expressed in total electron content units (TECU) as:

$$
\mathrm{TEC}=\int_{\mathrm{R}}^{\mathrm{S}} N_{\mathrm{e}} \mathrm{ds}
$$

where $1 \mathrm{TECU}=1 \times 10^{16}$ electrons $/ \mathrm{m}^{2}$ and $N_{\mathrm{e}}$ is the total number of the accumulated electrons in each square meter area through the differential distance (ds) along the path from the satellite to the receiver on the ground.

Employing the applications of GPS, there have been so far many researches carried out over various low-latitude and equatorial regions in the world, especially during the solar minimum phase. Based on the findings, the researchers have stated their own views regarding the characterization of the variation of the GPS-TEC of the specific ionospheric region in a specific time. Olwendo et al. (2012a), for instance, found the semiannual variation with two maxima occurring in the months of March-April and September-October. They also reported that seasonal variations in the nighttime TEC reveal semiannual periodicity with high background levels observed in the equinoctial months and low background levels in solstice over the Kenyan regions. In addition, Olwendo et al. (2012b) found out that the highest and the least monthly VTEC values are observed in the equinoctial months and in the June solstice months, respectively, during the period of 2009 to 2011 over the same regions (Kenyan regions). Shimeis et al. (2014) on the transient variations of vertical total electron content over some African stations from 2002 to 2012 noted that the diurnal variation of the VTEC presents multiple maxima during the equinox from 2005 to 2008 and during the summer solstice from 2006 to 2012. According to their findings, a nighttime VTEC enhancement and winter anomaly are also observed during the study period. They also explained that during the deep solar minimum (2006 to 2009) the diurnal variation of the VTEC observed over Alexandria is similar to the diurnal variation observed during quiet magnetic period at equatorial latitudes. Ouattara et al. (2012) in connection with seasonal TEC variability in West Africa equatorial anomaly region noted that, during equinoxes, the TEC shows dome profiles, and during solstices, the profiles are more complex with dome and multi-peaks. Akala et al. (2013) on the comparison of equatorial GPS-TEC observations over an African station and an American station during the minimum and ascending phases of solar cycle 24 showed that the maximum and minimum seasonal VTEC values are observed in the March equinox and solstices, respectively, during the solar minimum phases in both the African and American stations. However, during the ascending phase of the solar activity, the maximum values were recorded during the December solstice and minimum during the June solstice. Le Huy et al. (2014) on the time variations of the total electron content in the Southeast Asian equatorial ionization anomaly for the period 2006 to 2011 also showed that, during the deep solar minimum (2008 to 2009), the amplitude of crests of ionization becomes small during several months in summer and winter. According to their findings, both crests move significantly equatorward in winter than other seasons, and there is a tendency for both crests to appear earlier in winter and later in summer. Galav et al. (2010) also depicted as the seasonal variations in daytime TEC show a semiannual periodicity, with a minimum in winter over the Indian regions. In addition, over a low-latitude Singapore station, Kumar et al. (2014) have noted that the GPS-TEC values get decreased between 0300 and 0430 UT and started to increase between 0430 and 0930 UT during the period of 2011. They have also depicted that the TEC values are found to be highest during the equinoctial months during the period of 2010. D'ujanga et al. (2012) on total electron content variations in equatorial anomaly region showed that the highest TEC values occurred in the time interval between 1300 and 1700 local time (LT) during the period of 2010 over the Uganda region, with the highest values being exhibited during equinoctial months. Similar studies in other regions have been conducted by Huang and Cheng (1995), Huang and Cheng (1996), Tsai et al. (2001), Walker et al. (1994), Walker and Ma (1972), Wu et al. (2004, 2008), and Zhao et al. (2009) using various satellites and techniques.

However, over Ethiopia, very few researches have been so far conducted to assess features of the ionospheric TEC variability during both the low and the high solar activity phases. Nigussie et al. (2013) and Asmare et al. (2014) in connection with the IRI model validation have, of course, attempted to see the TEC variability over the region. Nevertheless, nobody has so far adequately studied the GPS-TEC variability, especially during the high solar activity phase. Hence, this is the first extensive study conducted to observe the pattern of the diurnal, monthly, and seasonal GPS-TEC variability during both the low (2008 to 2009) and the high (2012 to 2013) solar activity phases over the African sector with a focus over the Ethiopian regions.

\section{Methods}

\section{TEC from dual-frequency GPS receivers}

Employing dual-frequency GPS observations, it is possible to calculate the estimates about GPS-derived ionospheric TEC. According to different findings (e.g., Ciraolo et al. 2007; Mannucci et al. 1998), the GPS receiver measurements are important to estimate the electron density along a ray path 
between a GPS satellite and receiver on the ground. In addition to eliminating ionospheric errors in the estimation of TEC, dual-frequency GPS receivers can provide integral information about the ionosphere and plasmasphere by computing the differential of the code and carrier phase measurements (Ciraolo et al. 2007; Klobuchar et al. 1996; Nahavandchi and Soltanpour 2008). As a result, the GPSTEC estimated by the dual-frequency receivers is proposed as an input to an assimilative model of the ionosphere (Misra and Enge 2006). Thus, the GPS data recorded in the dualfrequency receivers have been utilized for this study, and the GPS-TEC data were obtained employing pseudo range and carrier phase measurements given as follows. The TEC from the pseudo range measurement is given by:

$$
\mathrm{TEC}_{P}=\frac{1}{40.3}\left[\frac{f_{1}^{2} f_{2}^{2}}{f_{1}^{2}-f_{2}^{2}}\right]\left(P_{2}-P_{1}\right)
$$

Similarly, the TEC from carrier phase measurement can be given as:

$$
\mathrm{TEC}_{\Phi}=\frac{1}{40.3}\left[\frac{f_{1}^{2} f_{2}^{2}}{f_{1}^{2}-f_{2}^{2}}\right]\left(\Phi_{1}-\Phi_{2}\right)
$$

where $f_{1}$ and $f_{2}$ are frequencies transmitted by GPS satellites which are obtained from the fundamental frequency, $f_{\mathrm{o}}=10.23 \mathrm{MHz}$ as:

$$
\begin{aligned}
& \left(f_{1}=154, f_{\mathrm{o}}=1,575.42 \mathrm{MHz}\right), \\
& \left(f_{2}=120, f_{\mathrm{o}}=1,227.60 \mathrm{MHz}\right),
\end{aligned}
$$

and $\left(P_{2}-P_{1}\right)$ and $\left(\Phi_{1}-\Phi_{2}\right)$ are the differential code and phase measurements, respectively.

The integrated TEC from the receiver to satellite as shown is proportional to the accumulated effect by the time the signal arrives at the receiver. This affects the GPS range observables: a delay is added to the code measurements and advance to the phase measurements (Gao and Liu 2002). The GPS data in the receivers are recorded in the Receiver Independent Exchange (RINEX) format and is then converted to GPS observable files using a suitable model. These GPS observables are either code pseudo ranges $(P)$ or carrier phase $(\Phi)$ measurements. By cross-correlating the $f_{1}$ and $f_{2}$ modulated carrier signals which are generally assumed to travel along the same path through the ionosphere, the receiver obtains the time delay of the code and the carrier phase difference. These are used to calculate the pseudo range and differential carrier phase which result in the determination of the slant code TEC and slant phase TEC, respectively.

Although there is relatively much noise, TEC from code pseudo range measurements is free of ambiguity. On the other hand, in spite of the ambiguity, TEC from carrier phase measurements has relatively less noise (Gao and Liu 2002). To solve this problem, the pseudo range noise is reduced by smoothing GPS pseudo range data with carrier phase measurements. This technique is called carrier phase smoothing or carrier phase levelling (Hansen et al. 2000). For accurate TEC estimation, the Sardon et al. (1994) approach was followed by removing differential instrument biases as satellites, and receivers for the GPS observables are biased on the instrumental delays (Norsuzila et al. 2009). As a result, even though it is not completely absolute TEC, linearly combining both the code pseudo range and the carrier phase measurements for the same satellite pass is supposed to increase the accuracy of TEC (Klobuchar et al. 1996). Hence, this resultant absolute TEC is the so-called GPS-derived slant TEC (STEC) along the signal path between the satellite and the receiver. As the STEC measurements are taken from different GPS satellite observed at arbitrary elevation angles, the GPS signals cross largely different portion of the ionosphere. To compare the electron contents for paths with different elevation angles, the STEC must be transformed into equivalent VTEC by dividing it by the secant of the elevation angle at a mean ionospheric height as shown in Equation 5. According to Norsuzila et al. $(2008,2009)$, this height usually ranges from 250 to $350 \mathrm{~km}$ at mid-latitudes and from 350 to $500 \mathrm{~km}$ at equatorial. Hence, in this study, the height of maximum electron density, $h_{\mathrm{m}}=350 \mathrm{~km}$, has been taken, because at this height the ionosphere is assumed to be spatially uniform and simplified to be a thin layer; hence, this is considered as the height of maximum electron density at the F2 peak (Mannucci et al. 1998; Norsuzila et al. 2009). Moreover, it is worth converting STEC to VTEC as the VTEC is considered as a more compact parameter to characterize the TEC over a given receiver position and used as a good indicator for the overall ionization of the Earth's ionosphere (Komjathy and Langley 1996). Hence, the relationship between STEC and VTEC in terms of the zenith angle $\chi^{\prime}$ at the ionospheric piercing point (IPP) and the zenith angle $X$ at the receiver position can be given by:

$$
\mathrm{VTEC}=\operatorname{STEC}\left(\cos \chi^{\prime}\right)
$$

where

$$
\chi^{\prime}=\arcsin \left[\frac{R_{\mathrm{e}}}{R_{\mathrm{e}}+h_{\mathrm{m}}} \sin \chi\right]
$$

Substituting Equation 6 into Equation 5 and rearranging, we get:

$$
\text { VTEC }=\operatorname{STEC}\left\{\cos \left[\arcsin \left(\frac{R_{\mathrm{e}}}{R_{\mathrm{e}}+h_{\mathrm{m}}} \sin X\right)\right]\right\}
$$

Here, $R_{\mathrm{e}}$ is the Earth's radius in kilometers.

\section{Data sources and method of analysis}

For the study, the solar minimum (2008 to 2009) and solar maximum (2012 to 2013) phases were considered. The GPS-TEC data were inferred from the dual- 
frequency GPS receivers given in Figure 1. Table 1 also shows the geographic and geomagnetic coordinates and dip angles of the stations. As it can be seen in Figure 1, the GPS-TEC data observed with the eight GPS receivers have been used for the study. To get the required GPS-VTEC data, the method proposed by Ciraolo et al. (2007) has been used. In order to see the diurnal variation of the VTEC, sampled days (based on the availability of GPS data) from all stations described in Figure 1 have been considered during both phases. During the low solar activity period, to see the pattern of the hour-to-hour variation of the VTEC in each month and season, one representative day for each month from Nazret station during the period of 2009 has been considered, and some sampled days (depending on the available GPS-TEC data) for some months from Nazret and Robe stations during the period of 2008 have been used. To make comparisons between the variability of the VTEC values observed during both the low and high solar activity phases, some selected days (depending on the available GPS-TEC data) during the period of 2008, 2009, and 2013 from Arba Minch station have also been considered. Similarly, due to GPS data constraint, only some days (from January to April) were utilized during the period of 2013 to observe the pattern of the hour-to-hour VTEC values during the solar maximum phase. For the monthly and seasonal VTEC variation, the GPS-
VTEC data inferred from Nazret and Arba Minch stations during the period of 2009 and 2012, respectively, were considered. To see the monthly VTEC variation, the diurnal mean hourly VTEC values for the whole magnetically quiet days in each month were added and averaged. Similarly, to investigate the seasonal VTEC variations, the diurnal mean hourly VTEC values were added in each season and averaged. The basic intention here is not to see the monthly and seasonal VTEC variability in 1-h interval; it rather intended to visualize the overall pattern of the VTEC variations observed in each month and season. The seasons were classified as March equinox (February, March, and April), June solstice (May, June, and July), September equinox (August, September, and October), and December solstice (November, December, and January).

\section{Results and discussion}

\section{Diurnal variation of GPS-VTEC}

The results of the diurnal variation of GPS-VTEC are shown in Figures 2, 3, 4, and 5. During the solar minimum phase, the diurnal VTEC values attained their peak values nearly between 1000 and 1300 UT (1300 and 1600 LT), while their values get diminished in the nighttime hours and become minimum at dawn, mostly at around 0300 UT (0600 LT) as shown in Figures 2, 3, and 4. Moreover, the peak hourly values observed in the sampled days get enhanced in the equinox months and become minima in

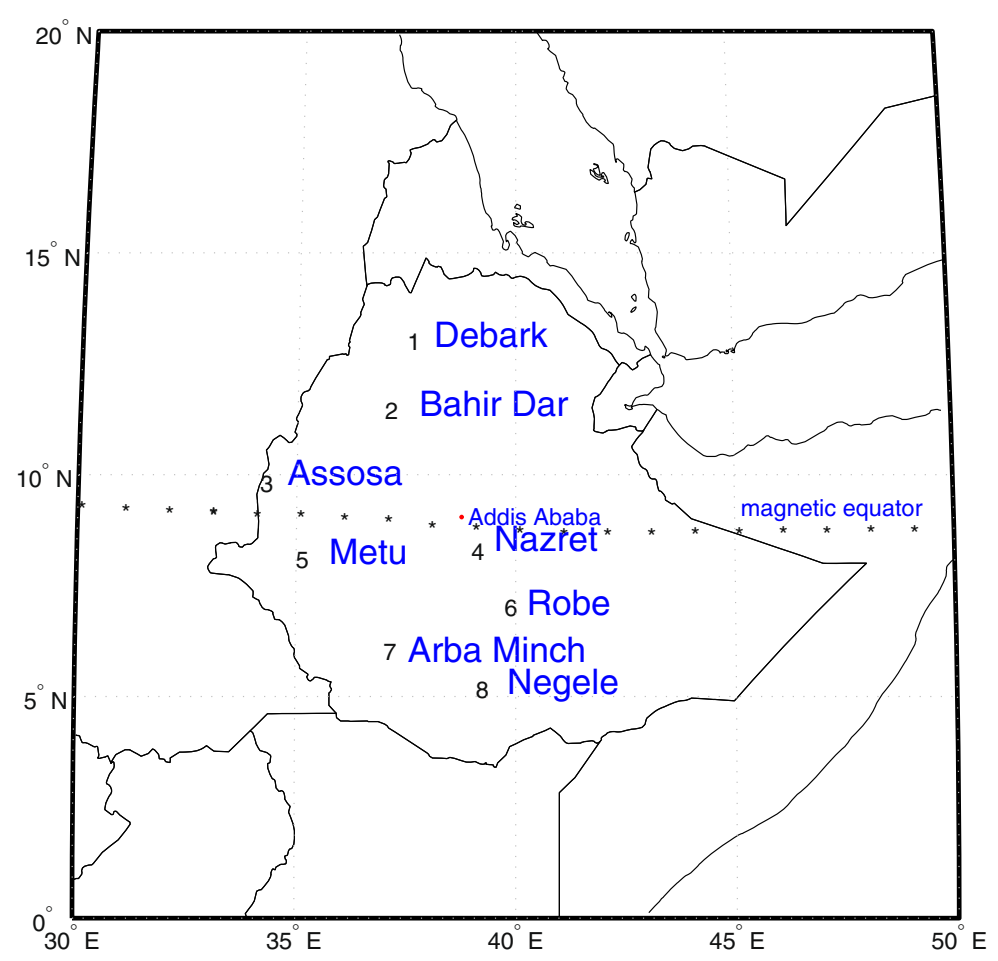

Figure 1 Locations of eight GPS receivers. 
Table 1 Geographic and geomagnetic coordinates of the GPS stations with their corresponding selected days

\begin{tabular}{|c|c|c|c|c|c|c|c|c|}
\hline \multirow{2}{*}{$\begin{array}{l}\text { Station } \\
\text { number }\end{array}$} & \multirow[t]{2}{*}{ Station } & \multirow[t]{2}{*}{ Code } & \multirow{2}{*}{$\begin{array}{l}\text { Geographic } \\
\text { coordinates } \\
\text { Lat. }\left({ }^{\circ} \mathrm{N}\right) \text {, } \\
\text { Long. }\left({ }^{\circ} \mathrm{E}\right)\end{array}$} & \multirow{2}{*}{$\begin{array}{l}\text { Geomagnetic } \\
\text { coordinates } \\
\text { Lat. }\left({ }^{\circ} \mathrm{N}\right) \text {, } \\
\text { Long. }\left({ }^{\circ} \mathrm{E}\right)\end{array}$} & \multirow{2}{*}{$\begin{array}{l}\text { Dip } \\
\text { angle }\end{array}$} & \multicolumn{3}{|c|}{ Year with corresponding sampled days } \\
\hline & & & & & & 2008 & 2009 & 2013 \\
\hline 1 & Debark & DEBK & $(13.15,37.89)$ & $(4.32,109.48)$ & 11.97 & - & - & $27 / 02$ \\
\hline 2 & Bahir Dar & BDMT & $(11.60,37.35)$ & $(2.64,108.97)$ & 8.03 & - & - & $25 / 02$ \\
\hline 3 & Assosa & ASOS & $(10.05,34.55)$ & $(0.69,106.17)$ & 3.20 & - & - & $04 / 03$ \\
\hline 4 & Nazret & NAZR & $(8.57,39.29)$ & $(-0.25,111.01)$ & 1.19 & $\begin{array}{l}21 / 03,25 / 04,21 / 06 \\
21 / 09,21 / 10,21 / 12\end{array}$ & $\begin{array}{l}03 / 01,02 / 02,21 / 03 \\
02 / 04,02 / 05,11 / 06 \\
11 / 07,21 / 07,22 / 07 \\
23 / 07 \text { 10/08, 24/09, } \\
02 / 10,02 / 11,01 / 12\end{array}$ & - \\
\hline 5 & Metu & METU & $(8.27,35.58)$ & $(-0.98,107.25)$ & -0.89 & - & - & $10 / 03,21 / 03,22 / 03$ \\
\hline 6 & Robe & ROBE & $(7.11,40.03)$ & $(-1.69,111.78)$ & -2.11 & $\begin{array}{l}21 / 03,05 / 04,21 / 06 \\
15 / 09,21 / 10,21 / 12\end{array}$ & - & - \\
\hline 7 & Arba Minch & ARMI & $(6.06,37.56)$ & $(-3.03,109.29)$ & -5.70 & $21 / 03,22 / 03,01 / 04,02 / 04$ & $\begin{array}{l}21 / 03,22 / 03,01 / 04 \\
02 / 04\end{array}$ & $\begin{array}{l}\text { 28/01, 26/02 10/03, } \\
21 / 03,22 / 03,01 / 04 \\
02 / 04\end{array}$ \\
\hline 8 & Negele & NEGE & $(5.33,39.58)$ & $(-3.60,111.35)$ & -6.81 & - & - & $02 / 04,03 / 04$ \\
\hline
\end{tabular}

the June solstice months (see Figures 3 and 4). As shown in Figure 4, for example, the highest peak VTEC value of 28.2 TECU is observed in March and the least peak VTEC value of 14.37 TECU is observed in July during the period of 2009. During the solar maximum phase, almost similar pattern is observed in the variability of the diurnal VTEC values. As shown in the figure (see the lower panel of Figures 2 and 5), the peak VTEC values are observed mostly in the time interval of 1000 to $1300 \mathrm{UT}$ (1300 to $1600 \mathrm{LT}$ ), and the least values are observed mostly at around $0300 \mathrm{UT}$ (0600 LT). In addition, the peak hourto-hour VTEC values observed in the high solar activity phase are larger than the corresponding peak values observed in the low solar activity phase, by more than two times (see Figure 2). For instance, on 22 March 2008 and 22 March 2009, the peak values of 27.96 and 30.85 TECU, respectively, had been recorded in Arba Minch station, while on 22 March 2013, a peak value of 65.03 TECU was recorded in the same station.

Furthermore, small enhancements in the VTEC values are observed in the nighttime variation of VTEC nearly between 1800 and 2000 UT (2100 and 2300 LT), especially for days considered from equinoctial months and then drops again (mostly after 2300 UT). According to Galav et al. (2010), this
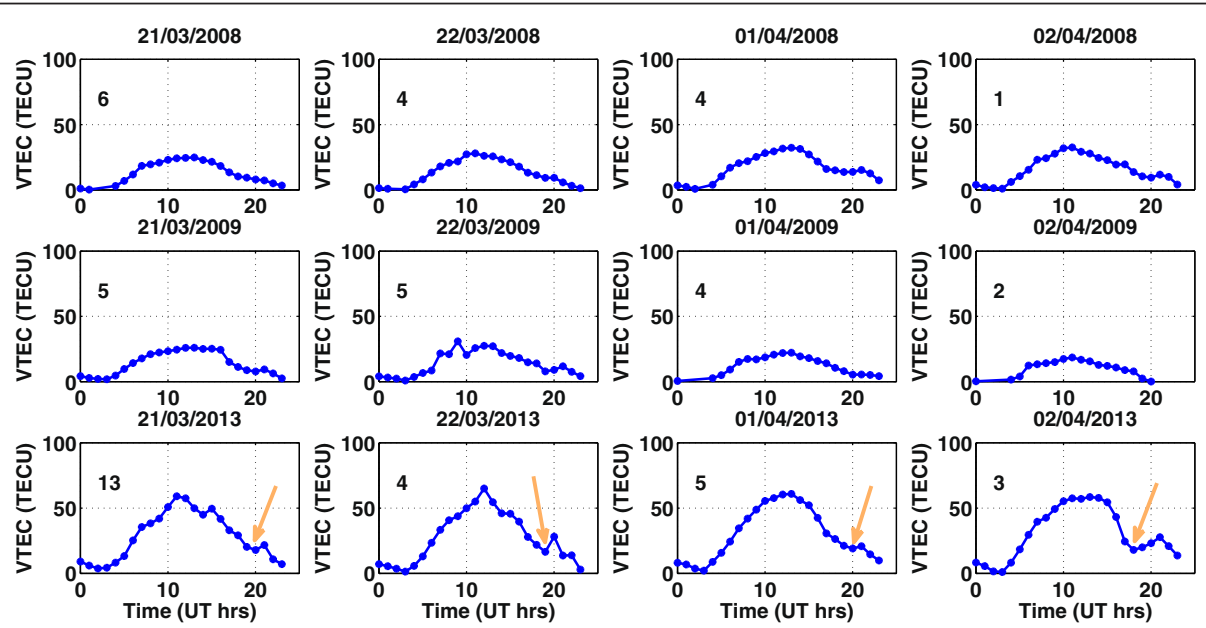

Figure 2 Comparison of the diurnal hourly VTEC variation over Arba Minch (station number 7) during the solar minimum (2008 to 2009) and solar maximum (2013) phases. The top, the middle, and the bottom panels show the VTEC variation in the sampled days with their corresponding Ap index in 2008, 2009, and 2013, respectively. Arrows indicate the time at which the nighttime enhancement of the VTEC values start. 

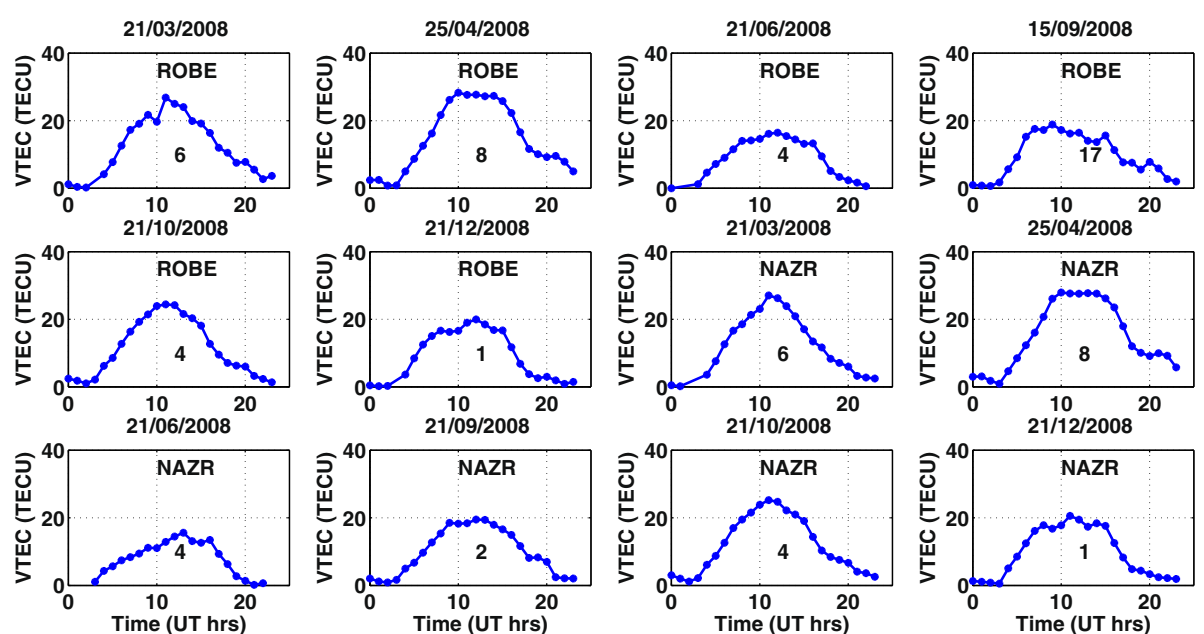

Figure $3 \mathrm{~A}$ graph to depict diurnal hourly VTEC variation during the solar minimum phase (2008). The figure shows the VTEC variation over Nazret (station number 4) and Robe (station number 6) in the sampled days with their corresponding Ap index.

may be due to the pre-reversal enhancement which is attributed to variation of the vertical $F$ region drifts which are large and upward during 18 to $20 \mathrm{LT}$ over the equator. The F region plasma is raised further up under the influence of the enhanced vertical drift at the equator during the equinoxes. This can delay the decay time of the plasma which results in high-level background density during the equinoctial months. As depicted in the lower panel of Figures 2 and 5, this event is the most pronounced on most of the days considered from equinoctial months during the high solar activity phase in the time interval of 1800 to 2000 UT (2100 to $2300 \mathrm{LT}$ ). Nonetheless, during the low solar activity period, the pre-reversal enhancement drifts are much smaller to affect any nighttime density enhancement at low latitude through the described process. This is clearly observed for days considered from the solstice months, especially in the June solstice months (see Figures 2, 3, and 4).

In general, according to the low-latitude ionospheric (LION) computer model, the ionospheric parameters such as TEC vary with the activities of the Sun, which includes diurnal, seasonal, solar cycle, and geomagnetic changes (Bittencourt et al. 2007). Moreover, when there are no vertical plasma drifts, the peak electron density maximizes near the magnetic equator in the late afternoon hours. Hence, these model results agree with the results determined in this work over the equatorial and the low-latitude (Ethiopian) regions, as shown in Figures 2, 3, and 4.

\section{Monthly and seasonal variation of GPS-VTEC}

The results of the monthly variation of GPS-VTEC are displayed in the left panels of Figure 6. The results show
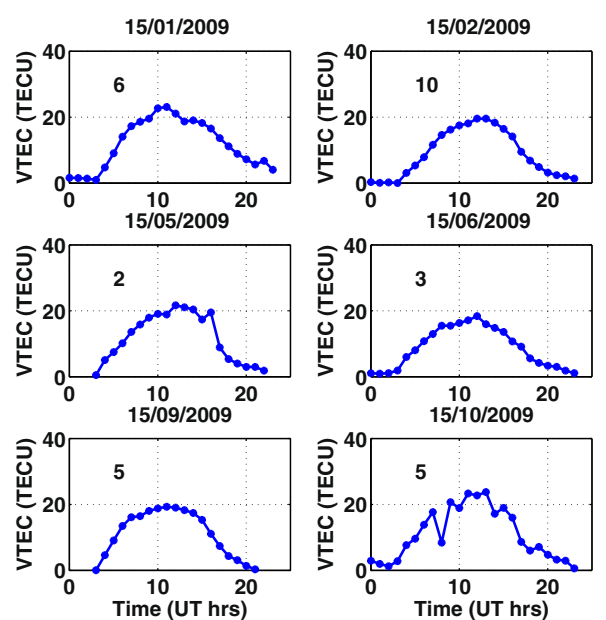
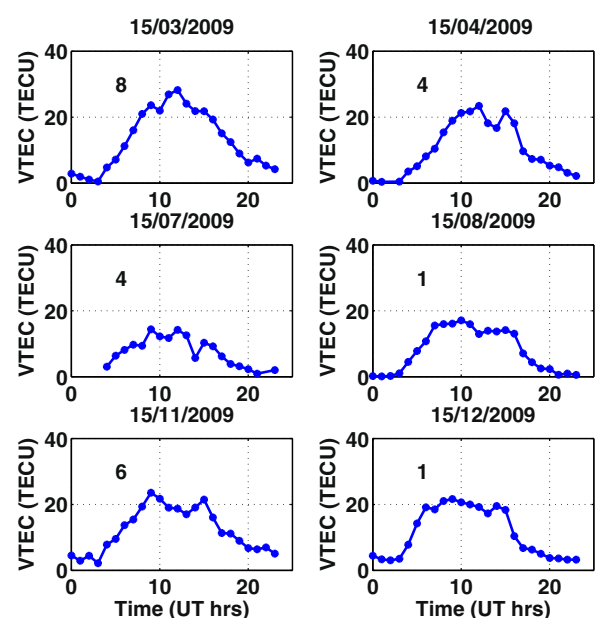

Figure 4 A graph to depict diurnal hourly VTEC variation during the solar minimum phase (2009). The figure shows the VTEC variation over Nazret (station number 4) in the sampled days with their corresponding Ap index. 

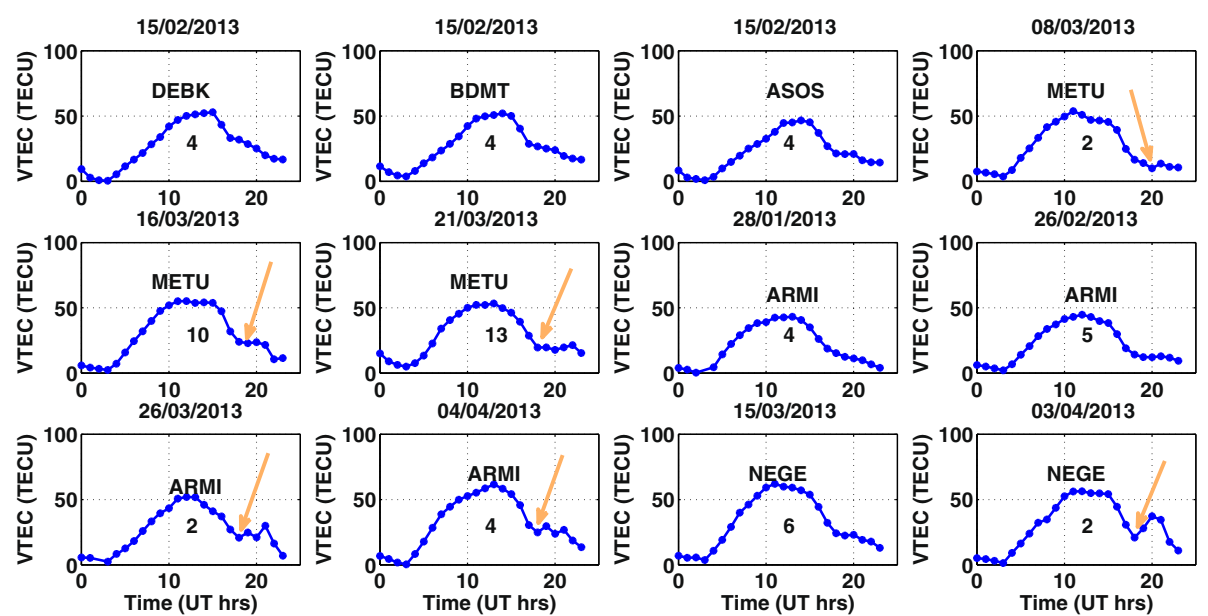

Figure 5 Diurnal hourly VTEC variation during the solar maximum phase (2013). The figure shows the VTEC variation in the sampled days with their corresponding Ap index over Debark, Bahir Dar, Asosa, Metu, Arba Minch, and Negele (with station numbers 1, 2, 3, 5, 7, and 8, respectively). Arrows indicate the time at which the nighttime enhancement of the VTEC values start.

that the monthly mean hourly VTEC has peak values in October. On the other hand, the least mean hourly VTEC value is observed in July during both the low and the high solar activity phases (see Figure 6a,c). The results of the seasonal mean of the hourly VTEC variations are given in the right panels of Figure 6. It has been depicted that the maximum diurnal mean hourly VTEC values are observed in the March equinox, while the least value of the seasonal diurnal mean hourly
VTEC values are observed in the June solstice as shown in Figure 6b,d during both the low and the high solar activity phases. When we compare the monthly and seasonal variability of the VTEC values during the low and the high solar activity phases, the peak monthly mean hourly VTEC value observed in October during the period of 2012 is larger than the peak value observed in 2009 by about $50 \%$. Similarly, the least diurnal mean hourly VTEC value observed in July during the period of

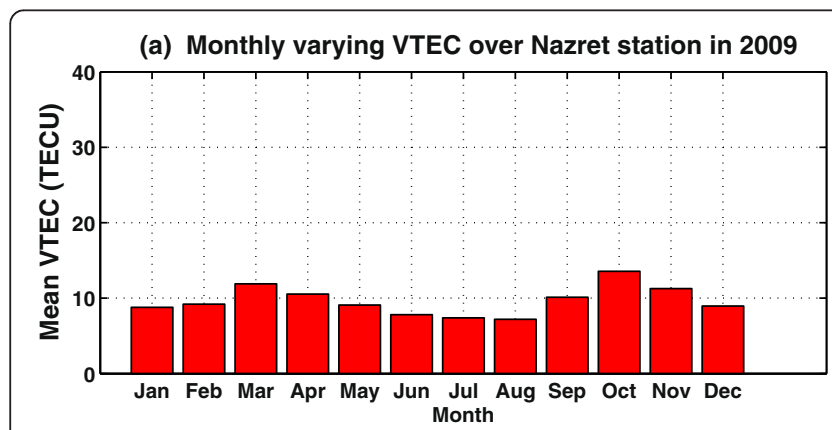

(c) Monthly varying VTEC over Arba Minch station in 2012

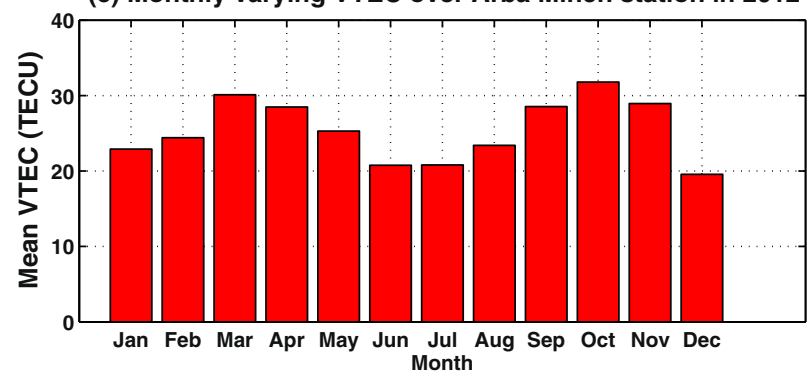

(b) Seasonal VTEC variation over Nazret station in 2009

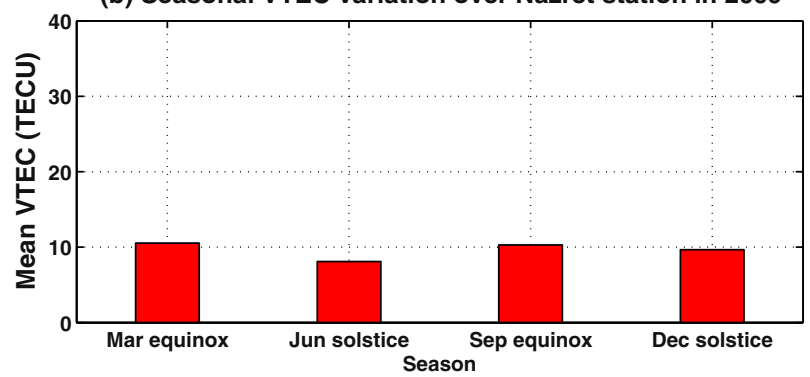

(d) Seasonal VTEC variation over Arba Minch station in 2012

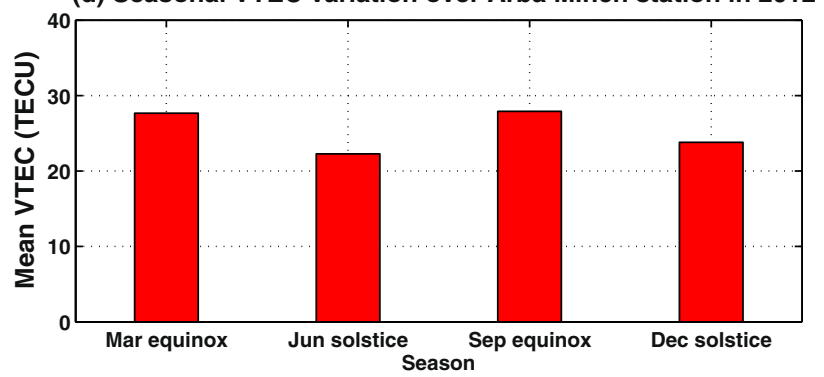

Figure 6 Monthly and seasonal diurnal means of hourly VTEC variation. The top panels $(\mathbf{a}, \mathbf{b})$ show the monthly and seasonal variation of the VTEC over Nazret (station number 4) during the low solar activity (2009), and the bottom panels (c, d) show the monthly and seasonal variation of the VTEC over Arba Minch (station number 7) during the high solar activity (2012) phase. 
2012 is larger (almost by three times) than the least value observed in the same month in 2009. The peak diurnal mean hourly VTEC value depicted in the March equinox in 2012 is also found to be larger than the peak value observed in 2009 by about $60 \%$, while the least value observed in the June solstice in 2012 is larger than the least value observed in the same season in 2009 by about 70\%. According to Johnson (1963), Rishbeth and Setty (1961), and Torr and Torr (1973), the least VTEC value observed in the June solstice (in the Northern hemisphere) during both the low and the high solar activity phases is possibly due to the asymmetric heating of the two hemispheres which results in the transportation of neutral constituents from summer to winter hemisphere thereby reducing the recombination rate. The fall of the recombination rate in winter can cause for the rise of the TEC values in winter than in summer solstice. The direction of the motion of the meridional component of the neutral wind may also be the cause for the decay of the ionization crest value during the summer solstice as it blows in the direction opposite to the plasma diffusion process originating from the magnetic equator (Bhuyan and Rashmi Rekha 2007; Wu et al. 2004).

In connection with the TEC variation during the extreme solar minimum period, Sharma et al. (2012) noted that the minimum and maximum seasonal values of VTEC are generally observed during the solstice and the equinoctial months, respectively, over the low (Delhi) and equatorial (Trivandrum) regions. They also noted that the observed weak ionospheric activities (such as low TEC values) during the period of 2007 to 2009 are due to the decrease of the solar activity. The low and high values of the VTEC observed during the low and the high solar activity phases, in our result, are mostly due to the decrease and increase of the solar activity, respectively. In addition, Olwendo et al. (2012b) found out that the highest and the lowest monthly VTEC values are observed in the equinoctial months and in the June solstice months, respectively, during the period of 2009 to 2011 over the Kenyan regions. These results are almost consistent with the result obtained in our study as shown in Figure 6.

\section{Conclusions}

The demands of developing countries (such as the African countries) to use modern technology for their better development are tremendously increasing. As a result, they are becoming the users of different types of devices (such as GPS) for various applications. Hence, this work investigates the pattern of GPS-TEC in the low and the equatorial regions of Africa with a focus over Ethiopia. In this paper, we have described the diurnal, monthly, and seasonal VTEC variation over Ethiopia during both the low (2008 to 2009) and the high (2012 to 2013) solar activity phases by considering eight GPS receivers installed recently at different regions of the country. It has been depicted that the diurnal peak VTEC values are observed in days considered from equinoctial months; while the minimum peak values are observed in days sampled from June solstice months. The diurnal variability of VTEC has shown the minimum values at around $0300 \mathrm{UT}(0600 \mathrm{LT})$ and the maximum values between around 1000 and 1300 UT (1300 and 1600 LT) during both the low and the high solar activity phases. In addition, the maximum and minimum monthly mean hourly VTEC values are observed in October and July, respectively, during both the low (2009) and the high (2012) solar activity phases. Similarly, the maximum and minimum seasonal mean hourly VTEC values are observed in the March equinox and the June solstice, respectively. Moreover, the monthly and seasonal peak VTEC values observed in the high solar activity phase are larger than those correspondingly observed peak VTEC values in the low solar activity phase by about $50 \%$ and $60 \%$, respectively.

\section{Competing interests}

The author declares no competing interests.

\section{Acknowledgements}

The author is very grateful to the World Data Center, UNAVCO, and NOAA for donating their free Dst (or Ap) index, GPS data, and daily sunspot number, respectively, for a better success of the early planned work.

Received: 16 May 2014 Accepted: 11 February 2015

Published online: 04 March 2015

\section{References}

Akala AO, Seemala GK, Doherty PH, Valladares CE, Carrano CS, Espinoza J, Oluyo S (2013) Comparison of equatorial GPS-TEC observations over an African station and American station during the minimum and ascending phases of solar cycle 24. Ann Geophys 31:2085-2096, doi:10.5194/angeo-31-2085-2013

Asmare Y, Kassa T, Nigussie M (2014) Validation of IRI-2012 TEC model over Ethiopia during solar minimum (2009) and solar maximum (2013) phases. Advances in Space Research., http://dx.doi.org/10.1016/j.asr.2014.02.017

Bagiya MS, Joshi HP, Iyer KN, Aggarwal M, Ravindran S, Pathan BM (2009) TEC variations during low solar activity period (2005-2007) near the equatorial ionospheric anomaly crest region in India. Ann Geophys 27:1047-1057

Bhuyan PK, Rashmi Rekha B (2007) TEC derived from GPS net work in India and comparison with IRI. Adv Space Res (COSPAR) 39:830-840

Bittencourt JA, Pillat VG, Fagundes PR, Sahai Y, Pimenta AA (2007) LION: dynamic computer model for the low-latitude ionosphere. Ann Geophys 25:2371-2392

Ciraolo L, Azpilicueta F, Brunini C, Meza A, Radicella SM (2007) Calibration errors on experimental slant total electron content (TEC) determined with GPS. J Geophys Res 81:111-120

D'ujanga FM, Mubiru J, Twinamasiko BF, Basalirwa C, Ssenyonga TJ (2012) Total electron content variations in equatorial anomaly region. Adv Space Res 50:441-449

Galav P, Dashora N, Sharma S, Pandey R (2010) Characterization of low latitude GPS-TEC during very low solar activity phase. J Atmos Terr Phys 72:1309-1317

Gao Y, Liu Z (2002) Precise ionospheric modelling using regional GPS network data. J Glob Positioning Syst 1(1):18-24

Hansen A, Blanch J, Walter T (2000) lonospheric correction analysis for WAAS: quiet and stormy. ION GPS, Salt Lake City, Utah, pp 634-642 
Huang YN, Cheng K (1995) Solar cycle variation of the total electron content around equatorial anomaly crest region in East Asia. J Atmos Terr Phys 57 (12):1503-1511

Huang YN, Cheng K (1996) Solar cycle variations of the equatorial ionospheric anomaly in total electron content in Asian region. J Geophys Res 101 (A11):24513-24520

Johnson FS (1963) Composition changes in the upper atmosphere. In: Thrane E (ed) Electron density distributions in the ionosphere and exosphere. North-Holland Publishing Company, Amsterdam, pp 81-84

Klobuchar JA, Parkinson BW, Spilker JJ (1996) lonospheric effects on GPS, in Global Positioning System: theory and applications. American Institute of Aeronautics and. Astronautics, Washington DC

Komjathy A, Langley RB (1996) The effect of shell height on high precision ionospheric modelling using GPS. In: Proceedings of the 1996 IGS Workshop, Silver Spring, MD., pp 193-203

Kumar S, Tan E, Razul S, Samson C, Slingh D (2014) Validation of the IRI-2012 model with GPS-based ground observation over a low-latitude Singapore station. Earth, Planets and Space, a Springer Open Journal. http://www.earth-planets.space.com/content/66/1/17

Le Huy M, Amory-Mazaudier C, Fleury R, Bourdillon A, Lassudrie-Duchesne P, TranThiT L, Chien N, Nguyen Ha T, Vila P (2014) Time variations of the total electron content in the Southeast Asian equatorial ionization anomaly for the period 2006-2011. Adv Space Res 54:355-368

Mannucci AJ, Wilson BD, Yuan DN, Ho CH, Lindqwister UJ, Runge TF (1998) A global mapping technique for GPS-derived ionospheric total electron content measurements. Radio Sci 33:565-582, doi:10.1029/97RS02707

Misra P, Enge P (2006) Global Positioning System: signals, measurements and performance. Ganga-Jumuna Press, Massachusetts

Moffett RJ, Hanson WB (1965) Effect of ionization transport on the equatorial F-region. Nature 206:705-706

Nahavandchi H, Soltanpour A (2008) Local ionospheric modeling of GPS code and carrier phase observation, vol 40, 309. pp 271-284

Nigussie M, Radicella SM, Damtie B, Nava B, Yizengaw E, Groves K (2013) Validation of the NeQuick 2 and IRI-2007 models in East-African equatorial region. Journal of Atmospheric and Solar-Terrestrial Physics. http://dx.doi.org/ 10.1016/j.jastp.2013.04.016

Norsuzila Y, Abdullah M, Ismail M (2008) Determination of GPS total electron content using single layer model (SLM) ionospheric mapping function. Int J Comp Sci Net Sec 8(9):154-169

Norsuzila Y, Abdullah M, Ismail M, Zaharim A (2009) Model validation for total electron content (TEC) at an equatorial region. Eur J Sci Res 28(4):642-648

Olwendo OJ, Baki P, Mito C, Doherty P (2012a) Characterization of ionospheric GPS total electron content (GPS TEC) in low latitude zone over the Kenyan region during a very low solar activity phase. J Atmos Solar Terr Phys 84-85:52-61

Olwendo O J, Baki P, Mito C, Doherty P (2012b) Comparison of GPS TEC variations with IRI- 2007 TEC prediction at equatorial latitudes during a low solar activity (2009-2011) phase over the Kenyan region. J Adv Space Res. http://dx.doi.org/10.1016/j.asr.2012.08.001

Ouattara F, Zoundi C, Fleury R, Amory-Mazaudier C, Lassudrie DP (2012) Seasonal TEC variability in West Africa equatorial anomaly region. Eur J Sci Res 77 (3):309-319, ISSN 1450-216X

Rishbeth H, Setty CSK (1961) The F-layer at sunrise. J Atmos Terr Phys 20:263

Sardon E, Rius A, Zarraoa N (1994) Estimation of the transmitter and receiver differential biases and the ionospheric total electron from Global Positioning System observations. Radio Sci 29(3):577-586

Sharma K, Dabas RS, Ravindran S (2012) Study of total electron content variations over equatorial and low latitude ionosphere during extreme solar minimum. Astrophys Space Sci 341:277-286

Shimeis A, Amory-Mazaudier C, Fleury R, Mahrous AM, Hassan AF (2014) Transient variations of vertical total electron content over some African stations from 2002 to 2012. Advance in Space Research. doi:10.1016/j.asr.2014.07.038

Torr MR, Torr DG (1973) The seasonal behavior of the F2-layer of the ionosphere. J Atmos Terr Phys 35:22-37

Tsai HF, Liu JY, Tsai WH, Liu CH, Tseng CL, Wu CC (2001) Seasonal variations of the ionospheric total electron content in Asian equatorial anomaly regions. J Geophys Res 106(A12):30363-30370

Walker GO, Ma JK (1972) Influence of solar flux and the equatorial electrojet on the diurnal development of the latitude distribution of total electron content in the equatorial anomaly. J Atmos Terr Phys 34(8):1419-1424
Walker GO, Ma JK, Golton E (1994) The equatorial ionospheric anomaly in electron content from solar minimum to solar maximum for South East Asia. Ann Geophys 12:195-209

Wu CC, Fry CD, Liu JY, Liou K, Tseng CL (2004) Annual TEC variation in the equatorial anomaly region during the solar minimum: September 1996-August 1997. J Atmos Terr Phys 66:199-207

Wu C-C, Liou K, Shan S-J, Tseng CL (2008) Variation of ionospheric total electron content in Taiwan region of the equatorial anomaly from 1994-2003. Adv Space Res 41:611-616

Zhao B, Wan W, Liu L, Ren Z (2009) Characteristics of the ionospheric total electron content of the equatorial ionization anomaly in the Asian-Australian region during 1996-2004. Ann Geophys 27:3861-3873

\section{Submit your manuscript to a SpringerOpen ${ }^{\odot}$ journal and benefit from:}

- Convenient online submission

Rigorous peer review

- Immediate publication on acceptance

- Open access: articles freely available online

- High visibility within the field

- Retaining the copyright to your article

Submit your next manuscript at $>$ springeropen.com 